\title{
Utilization of Job's Tear (Coix Lacryma-Joba L.) Flour as Composite for All Purpose Flour in Saltine Crackers
}

\author{
Cherry Jane Naingue Andoy ${ }^{1}$, Iren Vy Ruiz Enot $^{2}$, Aireen Jane Dominguez Mabaza ${ }^{3}$, \\ Ive Joy Cases Quillo, * \\ ${ }^{1}$ Dietary Department, Davao Doctors Hospital, Davao City, Philippines \\ ${ }^{2}$ Dietary Department, Valencia Polymedic General Hospital, Inc., Valencia City, Philippines \\ ${ }^{3}$ Dietary Department, St. Claire Hospital, Quezon, Philippines \\ ${ }^{4}$ Dietary Department, Don Carlos Doctors Hospital, Don Carlos, Bukidnon
}

\author{
Email address: \\ ivecq707@gmail.com (I. J. C. Quillo) \\ ${ }^{*}$ Corresponding author
}

\section{To cite this article:}

Cherry Jane Andoy, Iren Vy Ruiz Enot, Aireen Jane Mabaza, Ive Joy Quillo. Utilization of Job's Tear (Coix Lacryma-Joba L.) Flour as Composite for All Purpose Flour in Saltine Crackers. American Journal of Biomedical and Life Sciences. Vol. 7, No. 3, 2019 , pp. $52-56$. doi: 10.11648/j.ajbls.20190703.12

Received: May 17, 2019; Accepted: June 27, 2019; Published: July 9, 2019

\begin{abstract}
Nowadays, urbanization and smaller households are influencing Filipino consumers in procuring convenience food products. As a convenience food and a potential staple food, saltine crackers were made in this study by combining Job's tear (adlay) flour (Coix lacryma-Joba L.) and all-purpose flour to develop an improved convenience food product with high nutritional quality. All Purpose flour was added in different levels to Job's tear flour making four (4) treatments $(0,15,30$ and $45 \% \mathrm{w} / \mathrm{w}$ ) in the production of saltine crackers. The moisture, $\mathrm{pH}$ and ash content of the products were analyzed. The results of the test shows a significant difference in its ash content (\%) which ranges from 3.10-3.20\%, $\mathrm{pH}$ from 6.27-7.23 and moisture content (\%) $1.37-10.47 \%$. T4 (45\%) contains the highest moisture which means that the higher adlay flour added as composite, the higher the moisture content. T3 (30\%) shows the highest in ash content which is $3.20 \%$ and is primarily due to the ratio of the amount of all-purpose flour and adlai flour in the mixture. The sensory acceptability of the Adlay Saltine Crackers correspondingly shows a significant difference wherein $\mathrm{T} 3(30 \%)$ has the highest sensory score in terms of overall acceptability. T3 (30\%) is also the most acceptable in terms of color, aroma and texture while T4 (45\%) is the least acceptable in terms of its sensory properties.
\end{abstract}

Keywords: Adlay, Physicochemical Analysis, Sensory Evaluation

\section{Introduction}

Job's tear (Coix Lacryma-joba L.), also known as Adlay/Adlai in Mindanao, has obtained popularity in food researches not only in the Philippines but around the world [1]. Philippines is a tropical country that is dependent on grains as the staple food of its citizens. Many types and varieties of grains are grown in the in the world with rice as the second leading grain following corn [2]. Wide array of Adlay products around globe ranging from food, beauty care up to fashion are available. Belonging to same family of rice, corn and wheat, Job's tear is considered as a grass under Poecea family [3].
When compared to corn and rice, Adlay has a higher content of macronutrient (carbohydrates, protein, fat), minerals (Calcium, Phosphorus, Iron), B- vitamins (Niacin, thiamin and Riboflavin) and dietary fiber [4]. Adlay also has reportedly been a good source of potent antioxidants and phytochemicals which are good for the body [5, 6]. Crackers can be considered as "emergency food", "convenience food" or a "Grab-and-Go" type of food. Collins Dictionary defined these foods as something that is pre-prepared and requires little or no cooking thereby making readily available for consumption. It is a part of the usual diet and may be equivalent to rice in terms of its caloric content but is dependent also on the 
amount per serving. Various brands of crackers that claims different types of health benefits are widespread in the market. Recorded studies that uses minimally processed Adlay in single form or combination with other grains are already performed in butter cakes [7] and formulated ricelike grains [8].

The general objective of this study is to develop and assess the quality of Adlai Saltine Crackers. Specifically this study aims to assess the physico-chemical characteristics of the product and evaluate the sensory attributes in terms of color, aroma, taste and overall acceptability of the Adlai Saltine Crackers.

\section{Methodology}

\subsection{Materials}

The Adlay grains were procured at Northern Mindanao Integrated Research Center (NOMIARC), Dalwangan, Malaybalay City, Bukidnon. All the other ingredients such as the All-purpose flour, butter, salt, baking soda, sugar and commercial yeast were purchased from the local market.

\subsection{Preparation of Job's Tear Flour}

The preparation of the Job's tear flour followed the dry milling process wherein the grains were sorted, ground into fine powder and sieved and kept in a tight container [9].

\subsection{Formulation of Saltine Cracker Containing Job's Tear Flour}

The formulations used for preparation of crackers are outlined in Table 1. The crackers were prepared with the incorporation of Job's tear flour in $0,15,30,45 \%$ concentrations [10]. The use of sponge and dough method in making the saltine crackers was according to the method described by Han et al. (2010) [11]. The All-purpose flour, baking soda and other ingredients were weighed accurately. The dough was obtained through mixing the dry and liquid ingredients and allowing it to rest for 10 minutes before rolling out into uniform thickness [12]. The dough were cut out into rectangular shape and placed on paper lined pans about 1 inch apart and baked in a batch oven at $175^{\circ} \mathrm{C}$ for 10 minutes. The crackers were cooled to ambient temperature and packed.

Table 1. Formulation of crackers.

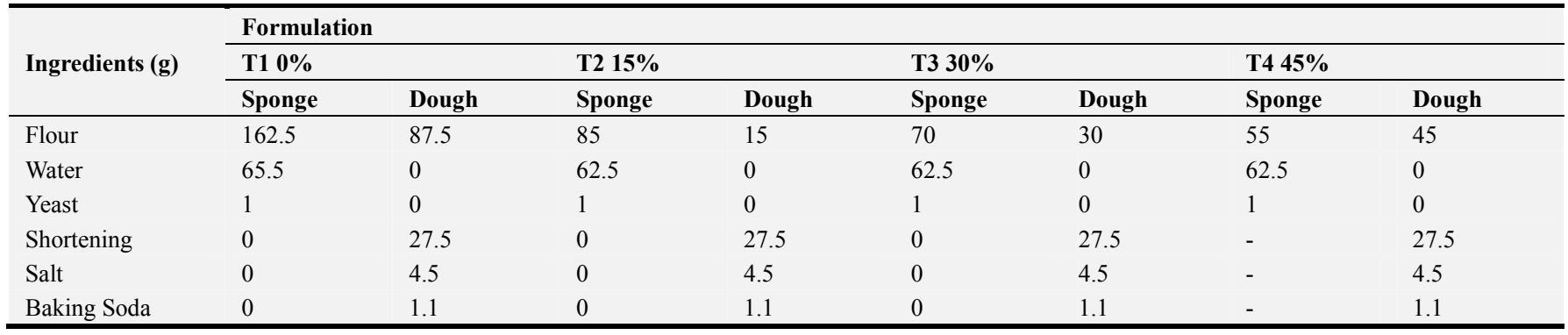

\subsection{Physicochemical Analyses}

The physicochemical properties of the Adlay crackers in four different treatments each with three (3) replicates were analyzed for moisture content, $\mathrm{pH}$ and ash content. The analysis was done at Soil and Plant Analysis Laboratory, Central Mindanao University.

\subsubsection{Sensory Analysis}

Sensory Evaluation was done by assessing the crackers using the acceptability test method by means of a 9-point hedonic scale. The sensory panel was composed of students from the College of Human Ecology, Central Mindanao University, Bukidnon. A total of 10 trained respondents were asked to evaluate the Adlay Saltine Crackers based on its color, aroma, taste, and overall acceptability. Each of the 10 panelists evaluated all of the three treatments allowing breaks in between. The design was replicated 3 times thus gathering a total of nine (9) data set from each panelist [13, 14].

\subsubsection{Statistical Analysis}

The data from sensory evaluation and physicochemical analyses were subjected to statistical analysis using ANOVA and comparison of means were done using Tukey's HSD test through the software SPSS ver. 20 (SPSS Inc., Chicago, USA). $\mathrm{P}<0.05$ indicated the statistical significance of the data. Results were also displayed as mean \pm standard error [15].

\section{Results}

Table 2 shows the triplicate means of the physicochemical analysis of the four (4) treatments 100:0, 85:15, 70:30, and 55:45 with their respective standard error. The physicochemical analyses performed were moisture content, $\mathrm{pH}$ and ash.

Table 2. Physicochemical composition of Adlay crackers.

\begin{tabular}{llll}
\hline Treatment & \% Moisture & pH & \% Ash \\
\hline T1 (control) & $1.37 \pm 0.42^{\mathrm{a}}$ & $6.27 \pm 0.08^{\mathrm{a}}$ & $3.18 \pm 0.08^{\mathrm{a}}$ \\
T2 $(15 \%)$ & $3.94 \pm 0.41^{\mathrm{b}}$ & $6.68 \pm 0.06^{\mathrm{b}}$ & $3.16 \pm 0.07^{\mathrm{a}}$ \\
T3 $(30 \%)$ & $3.93 \pm 0.70^{\mathrm{b}}$ & $6.77 \pm 0.06^{\mathrm{b}}$ & $3.20 \pm 0.12^{\mathrm{a}}$ \\
T4 $(45 \%)$ & $10.47 \pm 0.31^{\mathrm{c}}$ & $7.23 \pm 0.02^{\mathrm{c}}$ & $3.10 \pm 0.05^{\mathrm{a}}$ \\
\hline
\end{tabular}

* Means carrying same letters in a column for each factor do not differ significantly $(\mathrm{p}<0.05)$.

*Means for groups in homogeneous subsets are displayed. 
Table 3. Sensory Evaluation.

\begin{tabular}{llllll}
\hline Treatment & Color & Aroma & Texture & Flavor & Overall Acceptability \\
\hline T1 (control) & $7.60 \pm 0.12^{\mathrm{ab}}$ & $8.17 \pm 0.15^{\mathrm{a}}$ & $7.87 \pm 0.13^{\mathrm{a}}$ & $7.63 \pm 0.13^{\mathrm{b}}$ & $7.83 \pm 0.11^{\mathrm{ab}}$ \\
T2 $(15 \%)$ & $6.90 \pm 0.24^{\mathrm{b}}$ & $7.67 \pm 0.16^{\mathrm{a}}$ & $7.00 \pm 0.17^{\mathrm{b}}$ & $7.73 \pm 0.13^{\mathrm{ab}}$ & $7.27 \pm 0.17^{\mathrm{b}}$ \\
T3 $(30 \%)$ & $8.03 \pm 0.11^{\mathrm{a}}$ & $7.60 \pm 0.21^{\mathrm{a}}$ & $7.77 \pm 0.14^{\mathrm{a}}$ & $8.23 \pm 0.10^{\mathrm{a}}$ & $8.33 \pm 0.14^{\mathrm{a}}$ \\
T4 $(45 \%)$ & $5.10 \pm 0.25^{\mathrm{c}}$ & $6.13 \pm 0.24^{\mathrm{b}}$ & $4.77 \pm 0.22^{\mathrm{c}}$ & $6.00 \pm 0.19^{\mathrm{c}}$ & $4.97 \pm 0.23^{\mathrm{c}}$ \\
\hline
\end{tabular}

*Means carrying same letters in a column for each factor do not differ significantly $(\mathrm{p}<0.05)$.

*Means for groups in homogeneous subsets are displayed.

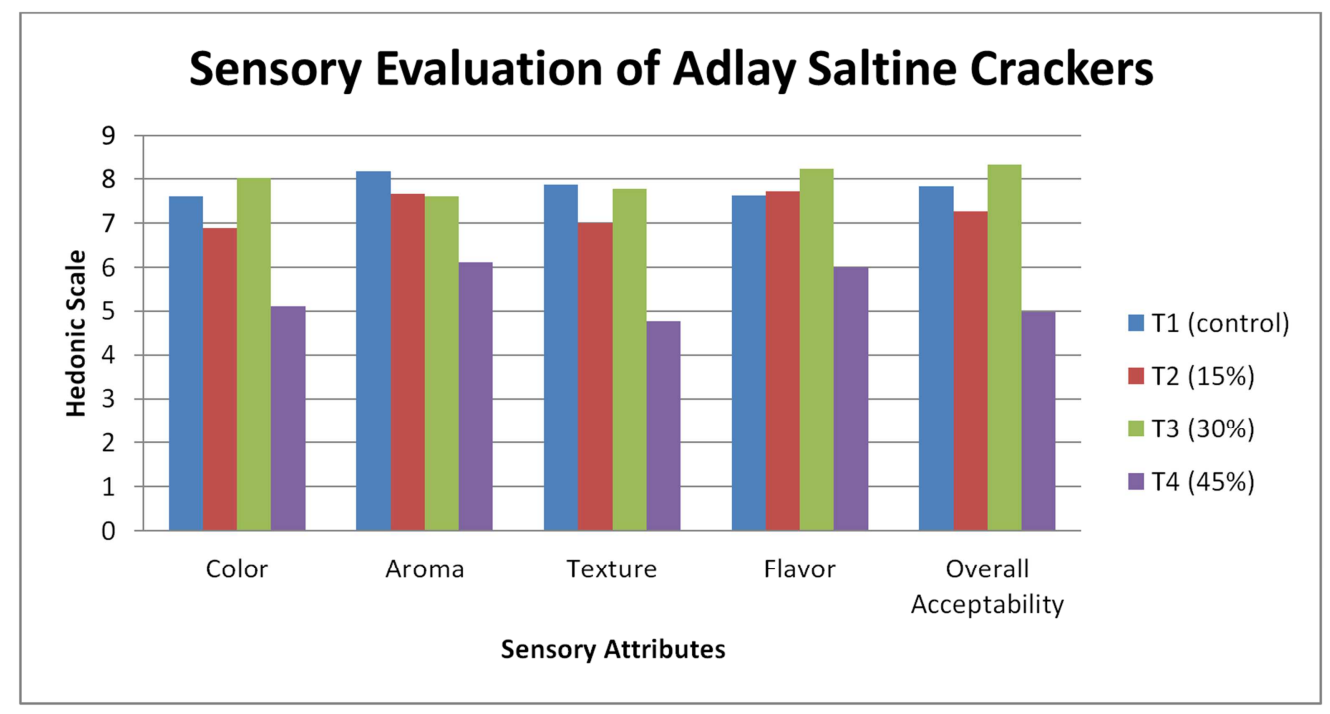

Figure 1. Sensory Evaluation Histogram.

\section{Discussion}

\subsection{Moisture Content}

One of the most essential analyses performed on food is moisture assay since water is a major constituent of most food products. Stability and shelf life of food products is greatly affected by moisture [15]. When foods had less moisture or dehydrated, microorganisms cannot grow and foods will not spoil [16]. Table 1 shows that the control (T1) has the least moisture content, followed by $\mathrm{T} 2$ and $\mathrm{T} 3$ respectively. T4 was found to be the highest in terms of moisture content. The high moisture content of treatment 4 closely relates to the study of Chhabra and Gupta (2015) [6] in which the moisture of adlay grains comprises $10.83 \%$. It is evident in Table 1 that the higher adlay flour added as composite, the higher the moisture content which is due to the adlay's high protein content $[17,18]$. Proteins found in adlay grains could enhance the molecular interactions between protein and protein, or protein and starch by heat. Hydration of water may be obstructed and could reduce the swelling volume of starch granules [19]. According to the study of Červenka et al. (2008) [20], analysis through linear regression revealed that the value of aw for biscuits is significantly influenced by moisture and total protein content. High moisture content considerably affects the shelf life of the product and influences mainly the rheological properties of the final product [21-23].

\section{2. pH Analysis}

In the case of $\mathrm{pH}$ content, data revealed that there were significant differences among the treatments except between $15 \%$ and $30 \%$ levels $(\mathrm{p}<0.05)$. In addition, the $\mathrm{pH}$ of the crackers slightly increased as the levels of JTF increased. Peñaflor and Peralta (2014) [24] stated that the type of cooking process can either decrease or increase the $\mathrm{pH}$ after processing depending on the composition of the food product. According to Pizzinato, A. \& Hoseney, R. (1980) [25], the addition of yeast adjusts the $\mathrm{pH}$ that allows enzymatic conditioning of the dough and also improves the flavor and texture of the finished crackers. Dough maturation is accomplished by the chemical reaction of yeast that produced alcohols and acids on protein of the flour. The increase in $\mathrm{pH}$ is suggestively associated with the Job's tear flour high protein content [21].

\subsection{Ash Analysis}

Ash is considered to be the mineral material in flour. Job's tears flour contains minerals such as magnesium, calcium, phosphorus, and traces of iron [6]. The highest recovered ash content comes from treatment $3(30 \%)$ which is $3.20 \%$. It is primarily due to the ratio of the amount of all-purpose flour and adlai flour in the mixture. The ash content of wheat ranges from 1.50 to $2.00 \%$. Pure endosperm is estimated to contain about $0.35 \%$ ash. Considering that the wheat kernel has $80 \%$ endosperm, it clearly shows that the non-endosperm parts of the kernel contains high amount of ash than the 
endosperm. The adlay's ash contents that were presented were also in lined with the study of Jomduang and Bunthawong (2018) [26] which indicates that Black Job's tears grains contained $2.12-2.29 \%$ ash and white Job's tears grains contained $0.33-0.69 \%$ ash.

\subsection{Sensory Evaluation}

Saltine Crackers incorporated with different levels of Job's tears flour were evaluated for their sensory qualities and general acceptability. A 9-point hedonic scale was used in comparing the different prepared crackers [14, 27]. All treatments of the saltine Job's tears crackers were subjected to sensory evaluation resulting to acceptability scores ranging from $8-4$ which means like very much to dislike slightly. The most pleasing in all four (4) treatments in terms of color was T3 which had a score of 8 followed by the control, then the T2 and the least acceptable being T4. In terms of Aroma, the most desirable was the control, followed by T2, then T3 with $\mathrm{T} 4$ the least desirable. The control also had the most acceptable texture, followed by the T3, then T2 and the least accepted texture being T4. In terms of flavor, T3 was the most favorable, followed by the $\mathrm{T} 1$ or the control, then $\mathrm{T} 2$ and $\mathrm{T} 4$ being disliked slightly by the respondents.

\section{Conclusion}

Job's tear flour (Coix lachryma-Jobi L.) was incorporated to all-purpose flour in the development of saltine crackers to improve the nutritional quality of the product. All Purpose Flour was substituted with different levels of Job's tear flour in four (4) treatments $(0,15,30$ and $45 \% \mathrm{w} / \mathrm{w})$ to produce saltine crackers. The moisture, $\mathrm{pH}$ and ash content were analyzed. The ash content (\%) ranged from 3.10-3.20\%, pH from 6.277.23 and moisture content (\%) $1.37-10.47 \%$. The sensory acceptability of the Adlay Saltine Crackers ranged from 4-8 which can be decoded to dislike slightly to like very much. The addition of Adlay flour at level 15\% showed only minute effect to the physicochemical properties of crackers. On the other hand, level $45 \%$ showed significant differences on the $\mathrm{pH}$ content. Moisture content was found to be greater as the level of Adlay flour increased which indicates that the higher level of adlay flour is added, the more its stability is compromised. High moisture content foods tend to spoil easily and therefore must be handled well. Sensory evaluation of crackers revealed that in terms of flavor and color, T3 (30\%) had the most accepted score. When it comes to the aroma and texture, the control (T1) had the most accepted score out of the four (4) treatments. Overall acceptability revealed that the 30:70 ratio of Adlay to all-purpose flour was the most accepted among the treatments presented.

\section{References}

[1] Arora, R. K. (1977). Job's-tears (Coix lacryma-jobi) — a minor food and fodder crop of northeastern India. Economic Botany, 31 (3), 358-366.
[2] Bock, M. A. (1991). Minor constituents of cereals. In K. J. Lorenz and K. Kulp (eds). Handbook of Cereal Science and Technology. (pp 555-594). Marcel Dekker, Inc., New York.

[3] Hore, D. K., \& Rathi, R. S. (2007). Characterization of Jobís tears germplasm in North-East India.

[4] Lee, H. J., Kim, S. S., Han, C. K., Oh, H. H., Kim, H. J., Lee, S. W.,... \& Kim, W. M. (2011). Antioxidative Activity and Quality Characteristics of Almond Cookies Prepared with Jobs tears (Coixlachryma-jobi L.) Chungukjang. Korean journal of food and cookery science, 27 (1), 43-54.

[5] Marangoni F \& Poli A. (2010). Phytosterol and cardiovascular health. Pharmacol Res, 61. 193-199.

[6] Chhabra, D., \& Gupta, R. K. (2015). Formulation and phytochemical evaluation of nutritional product containing Job's tears (Coix lachryma-Jobi L.). Journal of Pharmacognosy and Phytochemistry, 4 (3), 291.

[7] Kutchera, M., \& Krasaekoopt, W. (2012). The use of job's tear (Coix lacryma-jobi L.) flour to substitute cake flour in butter cake. AU Journal of Technology, 15 (4).

[8] Sisawad, S. and Chatket, I., (1985). Processing of Job's tears and beans. A report submitted to the processing of workshop on food and technology research and development. 25-27 September. Bangkok. 15p.

[9] Liaotrakoon, W., Liaotrakoon, V., Wongsaengtham, W., \& Rodsiri, S. (2014). Influence of dry-and wet-milling processes on physicochemical properties, syneresis, pasting profile and microbial count of job's tear flour. International Food Research Journal, 21 (5), 1745.

[10] Islam, M. Z., Taneya, M. L. J., Shams-Ud-Din, M., Syduzzaman, M., \& Hoque, M. M. (2012). Physicochemical and functional properties of brown rice (Oryza sativa) and wheat (Triticum aestivum) flour and quality of composite biscuit made thereof. The Agriculturists, 10 (2), 20-28.

[11] Han, J. J., Janz, A. M., Gerlat, M. (2010): Development of gluten-free cracker snacks using pulse flours and fractions. Food Res. Inter. 43 (2), 627-633.

[12] Manley, D. J. (2001). Biscuit, Cookie and Cracker Manufacturing Manuals: Sheeting, Gauging, Cutting, Laminating, Rotary Moulding, Extruding, Wire Cutting, Depositing, Troubleshooting Tips. Biscuit Dough Piece Forming. Manual 3. Woodhead.

[13] Onabanjo, O. O., \& Ighere, D. A. (2014). Nutritional, functional and sensory properties of biscuit produced from wheat-sweet potato composite. Journal of Food Technology Research, 1 (3), 111-121.

[14] Stone, H., \& Sidel, J. L. (2004). Introduction to sensory evaluation. Sensory evaluation practices. Boston, MA: Elsevier Academic Press. p, 1-19.

[15] Nielsen, S. S. (Ed.). (2010). Food analysis (pp. 139-141). New York: Springer.

[16] Gray, S. (2019). Introducing Food Dehydration. University of Missouri. Retrieved https://extension2.missouri.edu/gh1562

[17] MM, L., \& Targon, N. (1990). Characterization of the Storage Protein in Seed of Coix lacryma-jobi var. Adla y. J. Agric. Food Chem, 38, 631-635. 
[18] Ottoboni, L. M., Leite, A., Targon, M. L. N., Crozier, A., \& Arruda, P. (1990). Characterization of the storage protein in seed of Coix lacryma-jobi var. Adlay. Journal of agricultural and food chemistry, 38 (3), 631-635.

[19] Hamaker, B. R., \& Griffin, V. K. (1993). Effect of disulfide bond-containing protein on rice starch gelatinization and pasting. Cereal Chemistry, 70, 377-377.

[20] Cervenka L, Rezkova S, Kralovsky J (2008) Moisture adsorption characteristics of gingerbread, a traditional bakery product in Pardubice, Czech Republic. J Food Eng 84: 601607.

[21] Chaisiricharoenkul, J., Tongta, S., \& Intarapichet, K. O. (2011). Structure and chemical and physicochemical properties of Job's tear (Coix lacryma-jobi L.) kernels and flours. Suranaree J. Sci. Technol, 18, 109-122.

[22] Manohar, R. S., \& Rao, P. H. (1999). Effect of emulsifiers, fat level and type on the rheological characteristics of biscuit dough and quality of biscuits. Journal of the Science of Food and Agriculture, 79 (10), 1223-1231.
[23] Maache-Rezzoug, Z., Bouvier, J. M., Allaf, K., \& Patras, C. (1998). Effect of principal ingredients on rheological behaviour of biscuit dough and on quality of biscuits. Journal of Food Engineering, 35 (1), 23-42.

[24] Peňaflor, L., Elepaňo, A., and Peralta, E. (2014). Rice-Like Grains from Broken Rice (Oryza sativa L.) and Adlai (Coix lacryma-jobi L.). "Asian J. Agriculture and Food Science (2) 2014: 341-349.

[25] Pizzinato, A., and Hoseney, R. C. 1980. Rheological changes in cracker sponges during fermentation. Cereal Chem. 57: $185-188$.

[26] Jomduang, S., \& Bunthawong, O. (2018) Optimal PreTreatment Processes for Microwavable Puffed Job's Tears Grains.

[27] Meilgaard, M. C., Carr, B. T., \& Civille, G. V. (1999). Sensory evaluation techniques. CRC press. 